\title{
Breeding and mortality of Oriental White-backed Vulture Gyps bengalensis in Punjab Province, Pakistan
}

\author{
MARTIN GILBERT, MUNIR Z. VIRANI, RICHARD T. WATSON, J. \\ LINDSAY OAKS, PATRICK C. BENSON, ALEEM A. KHAN, SHAKEEL \\ AHMED, JAMSHED CHAUDHRY, MUHAMMAD ARSHAD, SHAHID \\ MAHMOOD and QASWAR ALI SHAH
}

\begin{abstract}
Summary
Populations of Oriental White-backed Vulture Gyps bengalensis and Long-billed Vulture G. indicus declined in India between the mid 1980s and late 1990s. Regional reports from India described declines of $95-100 \%$ across a wide area. This study was conducted to investigate the breeding success and pattern of mortality in two vulture colonies (Dholewala and Changa Manga) within Punjab Province, Pakistan between December 2000 and June 2001. Breeding success was found to be $62 \%$ in Dholewala and $59 \%$ in Changa Manga. A total of 668 sick and dead vultures were collected of which 591 were less than one month post mortem. No significant variation was found in the weekly mortality rate of adult and subadult vultures during the study period spanning winter through summer. A peak in mortality rate was observed during late April and early May that corresponded to mortality of newly fledged juveniles. Minimum annual mortality rate in the adult breeding population was calculated to be $11.4 \%$ and $18.6 \%$ in Dholewala and Changa Manga respectively. In a subsample of dead vultures $(n=185)$ visceral gout was found in $80 \%$ of adults, $63 \%$ of subadults, $19 \%$ of juveniles and $13 \%$ of nestlings. These mortality rates were consistent with a rapid population decline. Results imply that the mortality factor responsible for the decline in Gyps vultures described in India is also present in Pakistan and will potentially lead to a population decline of a comparable magnitude.
\end{abstract}

\section{Introduction}

Oriental White-backed Vulture Gyps bengalenesis has been described as the commonest vulture in the Indian subcontinent, with a range extending to south Vietnam and the Malay peninsula (Ali and Ripley 1968). The species is resident in Pakistan and is "widely distributed throughout the provinces of Punjab, Sind and the broader valleys of North West Frontier Province" (Roberts 1991). The species "prefers cultivated tracts with scattered trees and a high human population, being attracted to larger towns and cities where slaughterhouses and refuse tips offer more opportunity for obtaining food" (Roberts 1991).

Declines in Oriental White-backed Vulture populations were first reported in India by Prakash (1999) in Keoladeo National Park, Rajasthan. Maximum vulture counts within the park declined by $96 \%$ from 1985/1986 (max. 1,800) to 1998/ 
1999 (max. 86). Numbers of active nests showed a comparable decline of $95 \%$, with 353 nests located in 1987-88 and just 20 in 1998/1999. Breeding success was shown to have fallen from $82 \%$ of eggs laid in 1985/1986 to o\% in 1997/1998 and 1998/1999 (Prakash \& Rahmani1999). Numbers of Long-billed Vulture G. indicus sighted in Keoladeo National Park also declined, from a maximum count of 816 birds in 1985/1986 to only 25 in 1998/1999 (Prakash 1999).

Reports from numerous sources presented in Birdlife International (2001) suggested that the decline in populations of $G$. bengalensis and G. indicus were more widespread, extending across much of peninsular India. Observations suggest that the recently described Slender-billed Vulture G. tenuirostris may also have been affected (Birdlife International 2001). A reduction in the population of other sympatric species of Old World vulture, namely Egyptian Vulture Neophron percnopterus and Red-headed Vulture Sarcogyps calvus, have not been described, suggesting that the declines may be restricted to the genus Gyps.

A wide range of hypotheses have been proposed to explain a decline of this magnitude and rate. These include a reduction in food availability, loss of suitable nesting habitat, pesticide intoxication, deliberate poisoning, emerging infectious disease and calcium deficiency (Prakash 1999). Investigations into the cause of the declines have been underway since 1999 (Oaks et al. 2001, Cunningham et al. 2001, Pain 2001) and have largely suggested the involvement of an infectious disease or pesticide intoxication. Visceral gout was reported to be a "common finding" of vulture post-mortem examination in India (Pain 2001). Avian visceral gout should not be regarded as a disease entity, but as a clinical sign of any severe renal dysfunction (Lumeij 1994) and may be considered an end stage in a broad range of infectious and non-infectious disease processes. As yet no single underlying factor has been identified to account for the visceral gout that has been found in the vulture population.

This paper reports the first attempt to measure rates and identify patterns of mortality, and measure rates of reproduction in extant colonies of Oriental White-backed Vulture in Asia. Data are presented on breeding success and mortality patterns in Punjab Province, Pakistan between mid December 2000 and the end of June 2001. Data are also presented on the occurrence of visceral gout in relation to body condition and age class. A method of estimating mortality rate within breeding populations is described to draw spatial and temporal comparisons in this and future studies.

\section{Methods}

Our field studies were conducted in Punjab Province of Pakistan at two main sites (Dholewala and Changa Manga) and 13 peripheral sites (Figure 1). Dholewala ( $30^{\circ} 32^{\prime} 48^{\prime \prime} \mathrm{N}, 70^{\circ} 52^{\prime} 43^{\prime \prime} \mathrm{E}$ ) in Muzaffargar and Layyah Districts, is located east of the Indus River and comprises elevated canal banks lined with mature Sheesham Dalbergia sisoo trees that provide a linear distribution of suitable vulture nest sites. The land use is mainly agricultural, with cotton and wheat the principal crops. Changa Manga ( $31^{\circ} 04^{\prime} 10^{\prime \prime} \mathrm{N}, 73^{\circ} 58^{\prime} 39^{\prime \prime} \mathrm{E}$ ) is located in Kasur District (south of the city of Lahore) and is a forest plantation providing a twodimensional distribution of suitable vulture nest sites. It covers an area of 5,002 ha and contains a wide diversity of tree species including Sheesham and Kapok 


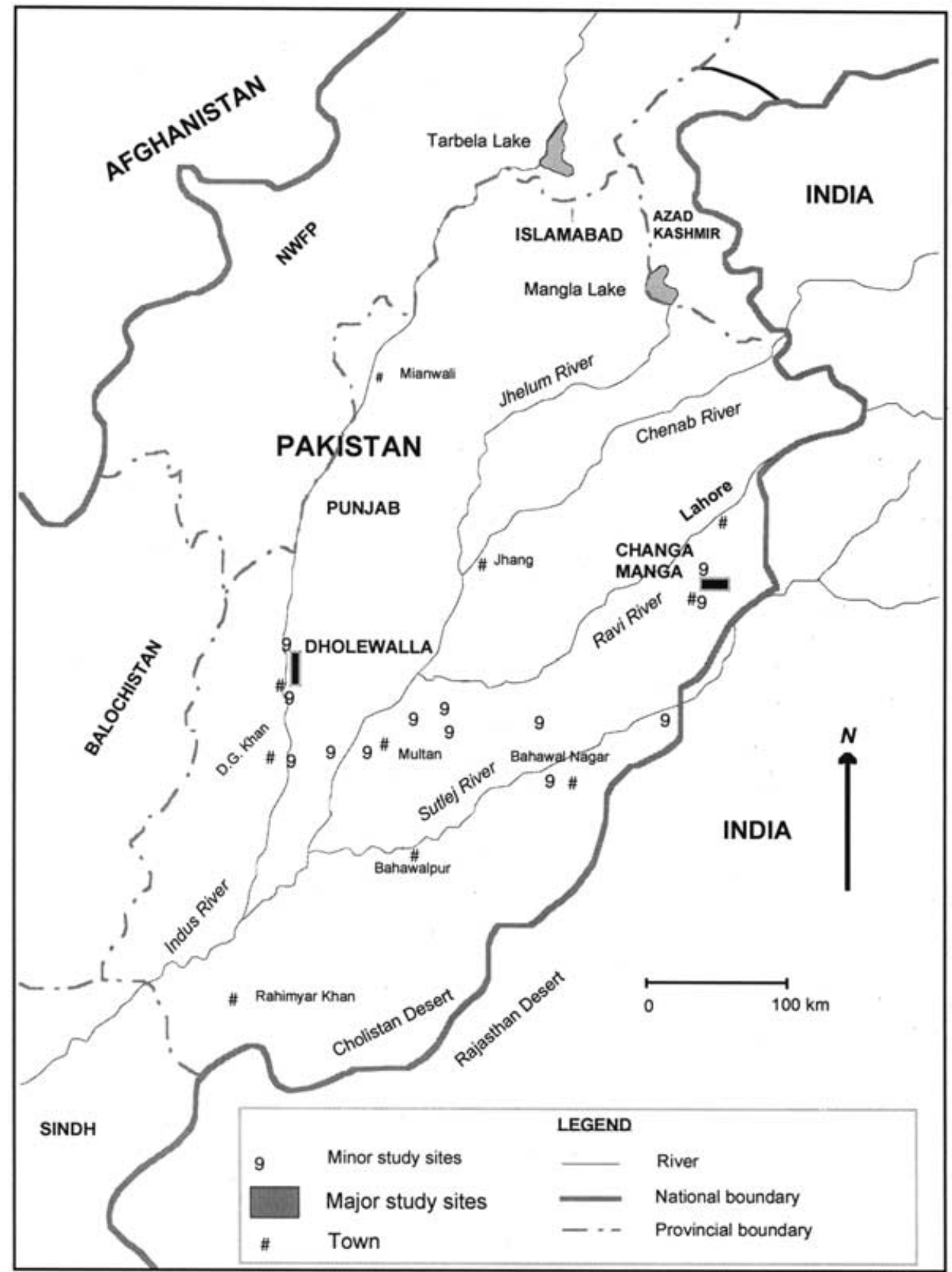

Figure 1. Location of the two main and 13 peripheral study sites.

Bombax ceiba. Abundant herds of domestic livestock occur at both sites. Dholewala lies $750 \mathrm{~km}$ and Changa Manga $550 \mathrm{~km}$ north-west of Keoladeo National Park, India. Dholewala and Changa Manga are $350 \mathrm{~km}$ apart.

Surveys began in mid December 2000 (Dholewala) and January 2001 (Changa 
Manga), when pairs were in late incubation and early nestling periods respectively. All nests in Dholewala colony were located and marked regardless of occupancy. A subsample of nests was randomly selected from all nests located for monitoring through the season. Four study plots were selected in Changa Manga, and all vulture nests were located and marked for monitoring. Nest observations were made from the ground, and an assessment of nesting activity was recorded. Nests were categorized as containing an adult vulture in incubating or brooding posture, an adult vulture or vultures present on the nest platform but neither seen to be brooding nor incubating, a confirmed sighting of a nestling, or as being devoid of signs of breeding activity.

Activities at the Dholewala study nest sites were recorded on 19 days between 13 December 2000 and 13 May 2001 and on 23-58 days (depending on the study plot) in Changa Manga, between 2 January and 23 May 2001. Forty-four nests were randomly selected from the total number of nests in Dholewala to estimate a mean nestling period. These nests were climbed on two to six occasions, starting as soon as possible after hatching in January and February to estimate nestling ages.

Using Postupalsky's (1974) criteria for assessing the reproductive success of raptors, an active nest was defined as a nest in which eggs had been laid, whereas an occupied nest was one in which an egg need not have been laid, but a minimum of nest building must have taken place. Postupalsky stressed that nest success can only be determined from the number of occupied nests that successfully fledge young. He also stated that it is necessary to survey early in the breeding season so that all territorial pairs will be included in an assessment of occupancy. Given that observations began during incubation it was not possible to determine occupancy and therefore nest success as defined in Postupalsky. Indeed, considering the high nest density and vulture traffic at both sites, it is unlikely that an accurate figure of occupancy could be obtained even if observations were to commence prior to laying. For this reason we used the active nest as the primary unit within this study. In practical terms, Postupalsky stated that nests where eggs were laid, young were raised, or an adult was observed adopting a posture consistent with incubation are sufficiently diagnostic to identify an active nest. Benson et al. (1990) present a method which may be used to obtain an estimated maximum number of active nests within a colony, using the daily rate of active nest failure within the observation period. This method is the same as that offered by Mayfield (1975) to analyse incomplete breeding data sets in passerine birds, and defines breeding success across a population in terms of the proportion of active nests that fledge successfully.

The date of nest failure or fledging was taken as the midpoint between the last confirmed observation of activity, and the first date from which no activity was observed. Exceptions to this occurred when the date of fledging or failure could be determined more precisely (such as in an observed fledging). Fledging was taken as the absence of a young vulture from the nest platform on or after the first date on which a known fledgling was observed in the colony. Beyond this date it was possible to distinguish between failed and fledged nests as nestlings were well grown by this stage and dead nestlings could be observed from the ground without difficulty.

We measured mortality by methodically collecting and removing dead vul- 
tures from beneath known nests throughout the breeding season. Study sites were searched for dead vultures on 105 (Dholewala) and 121 (Changa Manga) occasions between 1 January and 30 June 2001. Detailed necropsies were performed on those dead vultures where autolysis was not yet advanced. Where possible, the cause of death was determined from gross examination, and samples were collected for histological, microbiological and toxicological analysis. Observation of white uric acid precipitate over the surface or within the parenchyma of the liver, the kidneys, the lungs, within the pericardium, joints (femoro-tibial, tarso-metatarsal, shoulder), or any one of these was considered sufficient to indicate the presence of visceral gout. Houston (1976) used a system for scoring body condition of dead vultures by assessing the extent of fat reserves in the omentum, mesentery and subcutaneous tissue. Houston's scoring technique was simplified in this study and a bird was considered to possess omental fat reserves if deposits of fat formed a definite mass that obscured the intestines when abdominal musculature was resected. Birds with less extensive fat deposits were recorded as negative for omental fat.

The rate of decomposition varied greatly throughout the observation period, being significantly higher during the hot months of April, May and June. Evidence of uric acid accumulation was seen to persist several days after decomposition prevented detailed post-mortem examination. In cases where it was not possible to conduct a more detailed post-mortem, the skin, musculature and body wall were incised to expose the thoracic and abdominal viscera. An assessment of visceral gout and omental fat was made in these birds as described above, and where possible the sex of birds was determined. No assessment of articular gout was made in these birds.

We recorded the age class of dead vultures using plumage characteristics for adult (full adult plumage), subadult (one year to adult), juvenile (fledging to one year), and nestling. We estimated time since death in periods of $0-1$ day, 2-7 days, 8-30 days, and $>31$ days. The visual assessment of decomposition, and the frequency of visits to the site, ensured that times since death were categorized into these broad classes with reasonable accuracy. Vulture carcasses were removed from the site, or where this was not possible, carcasses were buried, to avoid double counting. An estimation of annual mortality rate was calculated by dividing the number of dead vultures $(D V)$ located within the study plots during the observation period ( $O P$ in days) by the number of breeding individuals (based on the number of active nests $(A N)$ at the start of the observation period) and extrapolating this over a 365 day period; using the formula:

$$
\frac{D V /(A N \times 2)}{O P} \times 365
$$

In our analyses of mortality rate we excluded all dead vultures classed as $2-7$ days post mortem located less than one week after the start of the observation period, all 8-30 day vultures located less than one month after the start of the observation period, all birds > 31 days post mortem and birds for which post mortem interval was unknown. Mortality rates were calculated for adults alone, and adults and subadults combined.

Patagial wing tags were fitted to 47 nestlings from 22 March to 4 April in Dholewala following the method outlined in Wallace et al. (1980). A further 24 
nestlings were tagged at a second colony, Toawala $\left(30^{\circ} 40^{\prime} 26^{\prime \prime} \mathrm{N}, 70^{\circ} 55^{\prime} 11^{\prime \prime} \mathrm{E}\right)$ between 1 and 2 April. At both sites the identity and location of wing-tagged nestlings were recorded whenever they were encountered or carcasses recovered (Dholewala 53 and Toawala 68 observation days). No attempt was made to relocate wing-tagged fledglings beyond the immediate vicinity of the nesting colonies.

\section{Results}

Breeding success

A total of 3,980 nests were located across the two primary and 13 peripheral study sites. Of these 2,430 were considered active, and at 1,293 no activity was observed. In Changa Manga 1,051 nests were located, of which 758 ( $72 \%)$ were active. Nesting density in Changa Manga was 0.15 active nests per hectare $(n=$ 758 nests within 5,002 ha of forest). In Dholewala 607 nests were located, of which breeding activity was recorded in $413(68 \%)$. Nesting density in Dholewala was 19.1 active nests per kilometre of linear transect $(n=413$ along $21.6 \mathrm{~km}$ ). In Dholewala $99 \%$ of nests were built on Sheesham. In comparison, there was a greater diversity of nest trees in Changa Manga where birds nested in 14 tree species (Sheesham 4\%, Albizzia lebbeck 17\%, Calistemon lanceolatum 14\%, Ficus sp. 4\%, Terminalia sp. 3\%, Trewia sp. 3\%, Bischofia sp. 1\%, Morus nigra 1\%, Angophora sp. $1 \%$, Cedreia sp.1\%, Grevillea sp.1\%, Pinus sp.1\%, Salmalia sp.1\%).

In Dholewala 307 nests were selected for monitoring of breeding success between December 2000 and May 2001. Of these, 237 were considered active in December, 66 showed no activity and status could not be determined for four. During the 144 day observation period fledging was confirmed in 153 , and nesting failure in 84 nests. Daily rate of nest failure during the observation period was 0.583 nests per day. The first fledgling was observed on 23 March, and mean fledging date was 19 April. Of 44 nests visited to assess nestling period, 36 were active in December. Nestlings fledged from 25 of these. Mean nestling period was determined to be 104 days. The incubation period was assumed to be 56 days as stated for the closely related African White-backed Vulture G. africanus (Mundy et al. 1992). The estimated number of active nests at laying was 246, with success of active nests calculated to be $62 \%$. This was calculated using the daily failure rate during the observation period.

We monitored 189 nests for breeding success in Changa Manga between January and May 2001. Of these, 177 were active in January, 11 showed no activity and status could not be determined for one. Nestlings fledged from 116 sites, and 61 failures were confirmed. Mean fledging date was 24 April. The estimated number of active nests at laying was 197, with a breeding success of $59 \%$.

\section{Mortality}

We collected 668 dead, sick and injured Oriental White-backed Vultures from all our study sites during the study period. One dead adult Eurasian Griffon $G$. fulvus was collected on 17 June, but was too decomposed to indicate the cause of death. Dholewala and Changa Manga accounted for 176 (26.3\%) and 186 (27.8\%) 
Table 1. Number and age distribution of dead, sick and injured vultures collected within study transects (excluding all birds that died prior to the study period) in Dholewala and Changa Manga, Pakistan (January to July 2001)

\begin{tabular}{llllll}
\hline Site & $\begin{array}{l}\text { Adults } \\
(\%)\end{array}$ & $\begin{array}{l}\text { Subadults } \\
(\%)\end{array}$ & $\begin{array}{l}\text { Fledglings } \\
(\%)\end{array}$ & $\begin{array}{l}\text { Nestlings } \\
(\%)\end{array}$ & $\begin{array}{l}\text { Total } \\
(\%)\end{array}$ \\
\hline Dholewala & $26(26.8)$ & $9(9.3)$ & $45(46.4)$ & $17(17.5)$ & $97(100)$ \\
Changa Manga & $25(26.9)$ & $23(24.7)$ & $39(41.9)$ & $6(6.5)$ & $93(100)$ \\
\hline
\end{tabular}

Table 2. Estimated time since death of dead vultures collected within study transects (excluding all birds that died prior to the study period) in Dholewala and Changa Manga, Pakistan (January to July 2001)

\begin{tabular}{lllllll}
\hline Site & 0-1 day & $2-7$ days & $8-30$ days & $>$ 31 days & Sick/injured & Unknown \\
\hline Dholewala & 20 & 64 & 12 & 2 & 1 & 1 \\
Changa Manga & 10 & 75 & 6 & 8 & 2 & 0 \\
\hline
\end{tabular}

dead vultures located respectively. The proportion of each age class known to have died within the study plots during the study period is summarized in Table 1. Post-mortem intervals of vultures located are summarised in Table 2. Adult annual mortality rate was calculated to be $11.4 \%$ in Dholewala, and $18.6 \%$ in Changa Manga. Combined adult and subadult mortality rate were calculated to be $15.3 \%$ in Dholewala and $36.2 \%$ in Changa Manga.

The weekly adult/subadult mortality rate using birds less than seven days post mortem was $1.54(\mathrm{SE}=0.33)$ and $1.77(\mathrm{SE}=0.26)$ vultures per week in Dholewala and Changa Manga respectively (Table 3, Figure 2). Dead fledglings began to appear from weeks 14 and 17 in Dholewala and Changa Manga respectively (Figure 3). Weekly fledgling mortality rate during the final 13 weeks of the study period was calculated to be $4.69(\mathrm{SE}=2.30)$ in Dholewala and $3.69(\mathrm{SE}=1.43)$ in Changa Manga. Fledgling mortality in the immediate vicinity of study nests was $27.5 \%$ in Dholewala ( $n=153$ successful nests) during 13 weeks and $33.6 \%$ in Changa Manga ( $n=116$ successful nests) during 10 weeks.

Eighteen (38\%) tagged fledglings were resighted in Dholewala in 53 days of observation and $14(30 \%)$ were recovered dead; two of these prior to fledging $(4 \%)$ and seven ( $15 \%)$ from their natal nests during the post-fledging dependence period (PFDP). One bird resighted in Dholewala was later found dead on its natal nest and so is included in the mortality figure stated. Ten $(37 \%)$ tagged

Table 3. Weekly and annual mortality rate of Oriental White-backed Vultures at Dholewala and Changa Manga, Pakistan

\begin{tabular}{|c|c|c|c|c|c|}
\hline Site & $\begin{array}{l}\text { Study } \\
\text { period } \\
\text { (weeks) }\end{array}$ & $\begin{array}{l}\text { Weekly } \\
\text { adult/ } \\
\text { subadult } \\
\text { mortality rate } \\
\text { (SE) }\end{array}$ & $\begin{array}{l}\text { Weekly } \\
\text { fledgling } \\
\text { mortality rate } \\
(\mathrm{SE})^{\mathrm{a}}\end{array}$ & $\begin{array}{l}\text { Annual } \\
\text { mortality rate } \\
\text { (adults only) }\end{array}$ & $\begin{array}{l}\text { Annual } \\
\text { mortality rate } \\
\text { (adult/ } \\
\text { subadult } \\
\text { combined) }\end{array}$ \\
\hline Dholewala & 26 & $1.54(0.33)$ & $4.69(2.31)$ & $11.4 \%$ & $15.3 \%$ \\
\hline Changa Manga & 26 & $1.77(0.26)$ & $3.69(1.43)$ & $18.6 \%$ & $36.2 \%$ \\
\hline
\end{tabular}

${ }^{a}$ Over 13 weeks post fledging. 


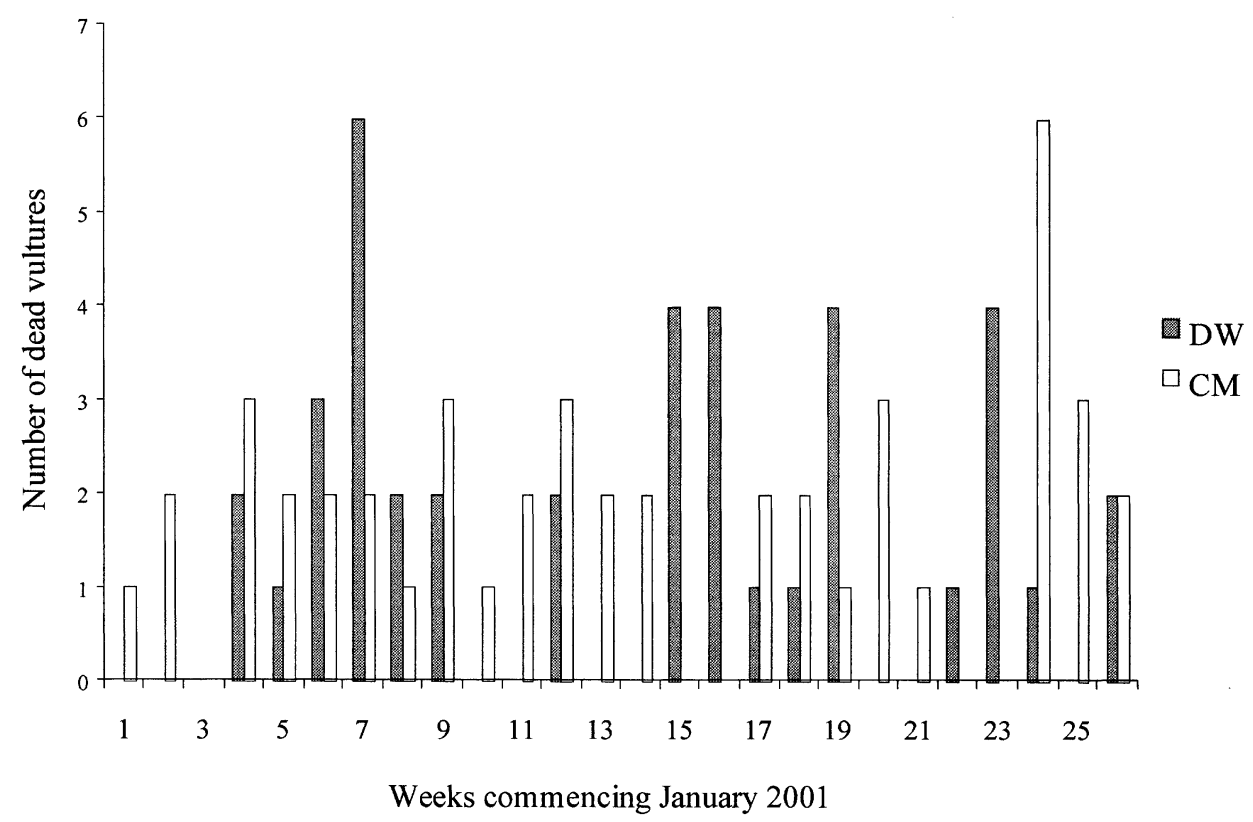

Figure 2. Dead adult and subadult Oriental White-backed Vultures found per week at Dholewala (DW) $(n=41)$ and Changa Manga (CM) $(n=46)$, Pakistan, during the study period.

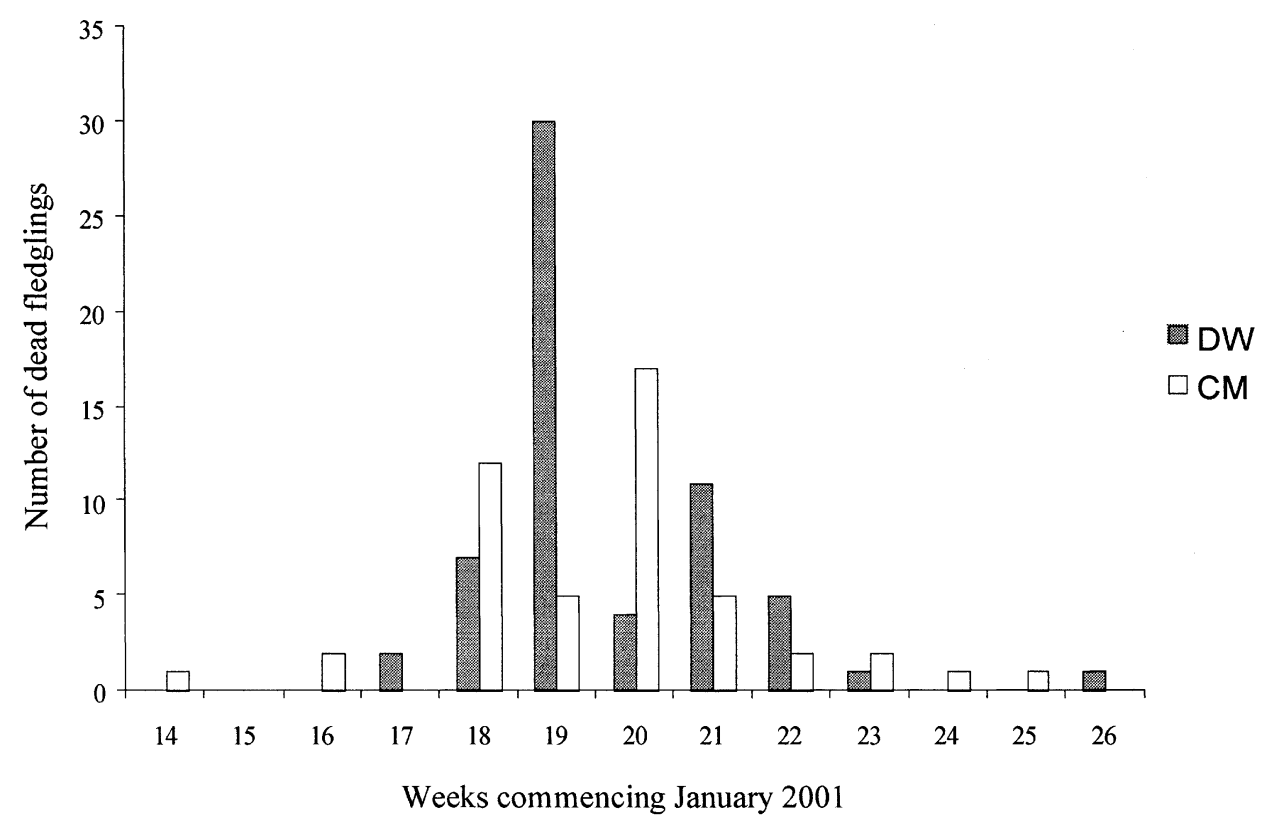

Figure 3. Dead fledgling oriental White-backed Vultures found per week at Dholewala (DW) $(n=61)$ and Changa Manga $(n=48)$, Pakistan, during the study period. 
fledglings were resighted in Toawala during 68 observation days. Six (22\%) were recovered dead, all of which had fledged, and were located away from their natal nest. Across all sites $9.9 \%$ of tagged fledglings $(n=20)$ and $8.2 \%$ of non-tagged fledglings $(n=219)$ were recovered from their natal nests.

\section{Gout}

An assessment of gout was made in 185 dead vultures (45 adults, 24 subadults, 93 fledglings, and 23 nestlings). Of these, 72 (39\%) had signs of visceral gout. Gout was found in $80 \%$ of adults, $63 \%$ of subadults, $19 \%$ of fledglings, and $13 \%$ of nestlings. Cases of gout were observed in every month between December and June. An assessment of sex was made in 49 dead vultures, of which 26 were male and 23 female. Twenty males and 15 females showed signs of visceral gout. Omental fat reserves were found in $81 \%$ of birds with visceral gout $(n=72)$ and $81 \%$ of birds with no signs of gout $(n=113)$. Detailed necropsies were conducted on 36 vultures. The primary cause of death was established in 12 cases, only one of which also had gout (Table 4). A further case was found to have a liver abscess suggestive of avian tuberculosis, but carcass decomposition precluded collection of samples. Primary cause of death could not be established in 22 cases, 20 of which had visceral gout (Table 4 ).

\section{Discussion}

Old World vultures conform to a life history strategy typical of large raptors and seabirds (Wynne-Edwards 1955, Amadon 1964, Newton 1979, Piper et al. 1981). They are long-lived, reproduce slowly, and adult survival is high in comparison with smaller birds. Among most animals including raptors, there is a strong positive correlation between body weight and adult survival, such that heavier species live longer, and are subject to lower mortality rates (Newton 1979). Oriental White-backed Vultures are comparable in weight to Bald Eagles Haliaeetus leucocephalus, and would be expected to have a similar annual adult survival rate of >0.91 (Newton 1979, Bowman et al. 1995). The stability of a non-migratory raptor population is generally dependent on three main factors: adult survival, non-adult survival and productivity (Watson 1990). For large, long-lived raptors, population stability is most sensitive to changes in adult survival, such that a small increase in adult mortality ( 1 - survival) relative to a similar change in non-adult survival will rapidly exceed the maximum productivity and force a population into decline.

Quantifying mortality rates in raptors is notoriously difficult. Recognized methods are broadly based on the rate of decline at which dead birds are recovered from a marked cohort (Newton 1979). Such studies are conducted over a period extending to years, and accuracy will be directly influenced by the proportion of the population marked, and the recovery rate of dead birds. In the context of vultures in south Asia, such long-term studies are impractical considering the rapid rate of decline observed and the urgency for remedial action. An alternative method uses plumage characters to assess age class distribution within a population and assumes any reduction in representation of each age class is due to mortality, and the population is stable. This method is only useful 
Table 4. Oriental White-backed Vultures case summaries of post-mortem examinations conducted between November 2000 and June 2001

\begin{tabular}{|c|c|c|c|c|c|c|c|}
\hline $\begin{array}{l}\text { Case } \\
\text { no. }\end{array}$ & Date & Site & $\begin{array}{l}\text { Age } \\
\text { class }\end{array}$ & Sex & $\begin{array}{l}\text { Body } \\
\text { fat }\end{array}$ & Gout & Provisional diagnosis \\
\hline 1 & 21 Nov oo & Changa Manga & Adult & M & Yes & Yes & Open \\
\hline 2 & 22 Nov oo & Lahore & Adult & $\mathrm{F}$ & Yes & No & Wire collision, trauma \\
\hline 3 & 23 Nov oo & Chichawatni & Juvenile & F & Yes & No & Hit by car, trauma \\
\hline 4 & $2 \mathrm{Dec}$ oo & Changa Manga & Adult & M & Yes & Yes & Avian tuberculosis \\
\hline 5 & 16 Dec oo & Katora & Adult & M & Yes & Yes & Open \\
\hline 6 & $16 \mathrm{Dec}$ oo & Katora & Adult & M & Yes & Yes & Open \\
\hline 7 & 16 Dec oo & Katora & Adult & $\mathrm{F}$ & Yes & Yes & Open \\
\hline 8 & 17 Dec oo & Katora & Adult & M & Yes & Yes & Open \\
\hline 9 & 17 Dec oo & Changa Manga & Adult & $?$ & $?$ & No & Human persecution \\
\hline 10 & 21 Dec oo & Dholewala & Adult & M & Yes & Yes & Open \\
\hline 11 & 22 Dec oo & Dholewala & Adult & M & Yes & Yes & Open \\
\hline 12 & 3 Jan o1 & Dholewala & Sub Adult & M & No & No & Open (CNS signs) \\
\hline 13 & 3 Jan o1 & Dholewala & I week & $?$ & No & No & Fell from nest, trauma \\
\hline 14 & 9 Jan 01 & Changa Manga & Sub Adult & $\mathrm{F}$ & No & No & Lead poisoning \\
\hline 15 & 14 Jan o1 & Changa Manga & Sub Adult & M & Yes & Yes & Open \\
\hline 16 & 15 Jan 01 & Changa Manga & Adult & $\mathrm{F}$ & Yes & Yes & Open \\
\hline 17 & 31 Jan 01 & Toawala & Sub Adult & $\mathrm{F}$ & Yes & No & Gunshot \\
\hline 18 & I Feb o1 & Toawala & $3-4$ weeks & $?$ & No & No & Fell from nest, trauma \\
\hline 19 & I Feb о1 & Dholewala & 2 weeks & $?$ & No & No & Fell from nest, trauma \\
\hline 20 & 5 Feb o1 & Changa Manga & Adult & $\mathrm{F}$ & Yes & Yes & Open \\
\hline 21 & 5 Feb o1 & Changa Manga & Adult & $\mathrm{F}$ & Yes & Yes & Open \\
\hline 22 & 12 Feb о1 & Toawala & Adult & $\mathrm{F}$ & No & Early & Diarrhoea, open \\
\hline 23 & 12 Feb o1 & Changa Manga & Adult & $\mathrm{F}$ & Yes & Yes & Open \\
\hline 24 & 18 Feb o1 & Dholewala & Adult & $?$ & Yes & Yes & Open \\
\hline 25 & 18 Feb о1 & Dholewala & Adult & $?$ & Yes & Yes & Open \\
\hline 26 & 18 Feb о1 & Dholewala & Adult & $?$ & Yes & Yes & Open \\
\hline 27 & $20 \mathrm{Feb}$ о1 & Dholewala & Adult & $?$ & Yes & No & Liver abscess, TB prob \\
\hline 28 & 5 Mar o1 & Changa Manga & Sub Adult & $\mathrm{F}$ & Yes & No & Normal ? (captured) \\
\hline 29 & 27 Mar o1 & Toawala & 70 days & $?$ & Yes & No & Fell from nest, trauma \\
\hline 30 & I Apr o1 & Toawala & 80 days & $?$ & Yes & No & Fell from nest, trauma \\
\hline 31 & I Apr о1 & Toawala & 90 days & $?$ & Yes & No & Fell from nest, trauma \\
\hline 32 & 5 Mау о1 & Dholewala & Fledgling & M & Poor & No & Diarrhoea, open \\
\hline 33 & 10 Jun 01 & Changa Manga & Fledgling & M & Yes & Yes & Open \\
\hline 34 & 10 Jun o1 & Changa Manga & Subadult & $\mathrm{F}$ & $?$ & Yes & Open \\
\hline 35 & 13 Jun o1 & Changa Manga & Adult & $\mathrm{F}$ & Yes & Yes & Open \\
\hline 36 & 13 Jun 01 & Changa Manga & Adult & M & Yes & Yes & Open \\
\hline
\end{tabular}

where age class can be assessed in the field with confidence. Although it is possible to subdivide a population of Oriental White-backed Vultures into broad age classes (juvenile, subadult, adult), knowledge of the moult sequence of the species is insufficient to accurately relate these plumages to age. With the unusually large number of dead vultures located in this study it is reasonable to assume that the population is not stable. For these reasons, and because mortality was so high that it was practical to collect dead birds in statistically useful numbers, we estimated annual mortality rate within the breeding population by assuming all birds collected from beneath nests were part of the breeding population, represented by the number of active nests multiplied by two. Calculating the mortality rate was therefore limited to only the breeding population. Our intention was 
to quantify vulture mortality as best we could, understanding the limitations imposed on the value by our assumptions, and with sufficient precision to provide an index of mortality rate that might be used in comparisons between geographical areas and with subsequent breeding seasons.

All methods of quantifying the mortality rate of wild populations of raptors are subject to bias and assumptions that may affect the validity of the result (Newton 1979). We made three important assumptions. First, we assumed that all dead birds from our subsample of the breeding population were located. In practice this was unlikely to be the case, as only birds dying in the immediate vicinity of their nests were found. Removal and consumption of dead birds by other scavengers such as dogs, almost certainly reduced the number located still further. Under-recording of dead birds probably led to an underestimate of the true annual mortality rate of the breeding population. Second, by extrapolating mortality measured during the study period to annual mortality, we assumed that mortality rate remained constant. We have shown that during the six months between January and July there was no significant variation in the weekly mortality rate of adult and subadult vultures, so this assumption may be correct. However, the identification of a seasonal pattern in the mortality of Asian vultures would have a significant impact on our understanding of its epidemiological characteristics, so the subject warrants further study throughout the year. This is difficult to achieve given that our method depends on the breeding population being tied to the breeding site, which occurs for only eight months of the year. Third, we assumed that all dead vultures found in the vicinity of nests were part of the breeding population. Oriental White-backed Vultures normally exhibit deferred maturity, so annual mortality rates calculated using the number of dead adults would normally be most accurate. However, an unknown proportion of the breeding population in Pakistan had not attained adult plumage and may be considered "immature breeders". Hence, mortality rates calculated using adult vultures only will underestimate mortality rate in the breeding population. Annual mortality rates calculated using a combination of adult and subadult vultures will account for "immature breeders", but may also include nonbreeding subadults, and should probably be considered an upper range for annual mortality rate within the breeding population.

The range of annual mortality rate was $11.4 \%$ (adults only) to $15.3 \%$ (adults and subadults combined) in Dholewala and $18.6 \%$ (adults only) to $36.2 \%$ (adults and subadults combined) in Changa Manga. Given our assumptions, we suggest the adult-only mortality rate considerably underestimates the true annual mortality of the breeding population. The range of annual mortality rates we present are higher than known and calculated mortality rates in stable populations of other raptor species of comparable body weight, demonstrating that the colonies studied were in a state of rapid decline during the study period. Studies at these sites are ongoing, and will provide data that will test the accuracy of these predictions.

Sharma (1970) recorded the breeding success of Oriental White-backed Vultures near Jodhpur, Rajasthan, as $96 \%$, though the definition of breeding success used was not stated. In Keoladeo, Prakash (1999) indicated breeding success rates of $82 \%$ in $1985 / 1986(n=244)$ and $\mathrm{o}$ in the $1997 / 1998(n=25)$ and $1998 / 99(n=$ 20) seasons. He defined breeding success as the number of birds raised to 
fledging per egg laid, so his results can be directly compared to this study. He indicated $20 \%$ of nest failure occurred prior to laying, $20 \%$ during incubation and 60\% during the nestling period in 1997/1998 and 60\% prior to laying, 10\% during incubation and 30\% during the nestling period in 1998/1999. Though our values of $62.1 \%$ and $58.8 \%$ in Dholewala and Changa Manga respectively in 2000/2001 are not as high as the pre-decline figures of Sharma (1970) or Prakash (1999) they are still far from the total disappearance of breeding activities observed in Keoladeo in the late 1990s.

It is important to recognize that our breeding success figures have been extrapolated using the known failure rate during the observation period to predict the number of active nests at laying. This method assumes that the rate of nest failure remained constant from laying to fledging. This introduces a potential source of error in our study as observations were largely made during the nestling period. The post-decline figures presented by Prakash (1999) indicated three times as many nests failed during the nestling period as during incubation in both 1997/1998, and in 1998/1999. Assuming that the incubation period in Oriental White-backed Vulture is equal to the 56 day incubation period seen in African White-backed Vulture (Mundy et al. 1992), and that our estimate of mean nestling period of 104 days is accurate, then Prakash's nest failure rate during the incubation period was 1.6 times greater than during the nestling period. A difference in failure rate of this magnitude in our study colonies would translate to an amended breeding success of $54.2 \%$ in Changa Manga and 57.5\% in Dholewala. At the opposite extreme, were we to assume that no nests failed prior to the start of the study, failure rate within our colonies would be $64.6 \%$ in Dholewala and 65.5\% in Changa Manga. In both cases it is clear that breeding success in the colonies studied is lower than the predecline data of Sharma (1970) and Prakash (1999).

Our findings of visceral gout in $78 \%$ of adult $(n=45)$ and $63 \%$ of subadult $(n=$ 24) vultures examined is consistent with preliminary findings of post-mortem examinations conducted in India (Pain 2001). It is possible that vultures are unusually susceptible to developing this condition, and that all cases need not be related. However, of 21 birds with visceral gout where a detailed post-mortem examination could be made, a primary diagnosis was only possible in one case (Case 4: avian tuberculosis). It is beyond the scope of this paper to cover the detailed clinical findings of the birds examined and this will be described in full in a separate publication. Suffice to say that lesions associated with the precipitation of uric acid were the only consistent findings made during the detailed necropsy of 20 birds with visceral gout. The lack of a firm diagnosis or lesions unrelated to uric acid in the majority of birds with gout was consistent and characteristic of the majority of dead vultures, but so far has done nothing to reveal the cause of mortality. This observation supports the hypothesis that cases of visceral gout are related and hence would suggest that the mortality factor responsible for the decline in India is also present in Pakistan.

The body condition scoring system used by Houston (1976) has been greatly simplified for use in this study. Houston's system defines nine classes of body condition based on deposits of fat in the mesentery, omentum and subcutaneous tissue. In this study we have scored birds with moderate to abundant omental fat reserves as "positive" for omental fat, which would correspond to a body condition score of 6-9 on Houston's scale. Therefore, it should not be assumed 
that birds scored as "negative" in our study are completely emaciated, but simply indicate that these birds have a body condition that would be considered moderate to poor.

Moderate to abundant reserves of omental fat were found in $81 \%$ of dead birds. This supports the assessment of Prakash (1999) that the observed mortality in Gyps vultures is unrelated to the availability of food. Prakash also states that prior to death vultures would remain immobile for "more than 30 days". It is clear from our study that this is not the case for the majority of vultures that ultimately die. Moderate to abundant levels of omental fat are unlikely to be found in a bird that remains immobile for a period in excess of one month, and would suggest that death in the majority of cases in this study followed a more acute clinical course.

Visceral gout was also recorded in juveniles and nestlings, although at a lower rate than was observed in adults and subadults. This may be due to a lower susceptibility to the condition than is seen in adult and subadult birds, a lower exposure to factors leading to visceral gout, or a low prevalence of gout cases relative to the incidence of other age-related mortality factors. It is likely that data on the occurrence of gout in nestlings has suffered from bias, with an overrepresentation of nestlings that have fallen from their nests. Mortality rate in fledglings greatly exceeded that of adult and subadult birds, representing $43 \%$ of birds that died during the study period. Mortality of fledglings was concentrated in a 13 week period between April and June. Comparison with other species of Gyps vultures suggests that high fledgling mortality may not be unusual for the species (Houston 1974, Piper et al. 1981, Robertson 1985, Benson 2000).

Benson (2000) stated that fledging corresponds to one of the periods of highest mortality for all birds, although this is very difficult to quantify in vultures due to the long distances birds may cover before dying. Studies of mortality in Cape Vulture G. coprotheres based on recovery of birds banded as nestlings suggested mortality rates in the first year in excess of $50 \%$ (Houston 1974) to $83 \%$ (Piper et al. 1981). Studies based on resighting of marked Cape Vultures at Potberg in South Africa (Robertson 1984) also predicted that first year mortality was between 71 and $81 \%$ (assuming that all birds that failed to return to the natal colony were dead). Parental care in Old World vultures continues for an extended period after fledging. During the post-feldging dependence period (PFDP) juveniles must return to the nest in order to be fed by their parents (Robertson 1985). Mortality in the PFDP is largely a consequence of the inability of young vultures to return to the nest (Benson 2000).

Our finding that $9.9 \%$ of dead wing-tagged fledglings $(n=20)$ and $8.2 \%$ of non-wing-tagged fledglings $(n=219)$ in this study were found in their natal nests represents further evidence that colonies surveyed were subject to unusual patterns of mortality. This group of fledglings was found in a position that would normally be considered compatible with survival. Data are insufficient to predict whether fledgling mortality within the nest was related to mortality of the parent birds or through gout-related death of the fledglings, although of four fledglings recovered from nests where an assessment of gout was made, the condition was identified in only one bird.

Although visceral gout was only found in a minority of juveniles and nestlings, the fact that it was found at all should be considered significant. If the hypothesis 
that gout-related deaths are connected is correct, then the presence of the condition in juveniles and nestlings would suggest that the mortality factor responsible for the condition is either vertically or horizontally transmissible from adults to offspring, or is inherently present in the vicinity of the colony itself.

In conclusion, this study supports the hypothesis that the mortality factor responsible for the decline in vulture populations in India is also present in Punjab Province, Pakistan. Breeding success at two colonies in Punjab is somewhat lower than pre-decline figures reported from India. Despite an elevated mortality rate and a depression in breeding success, large colonies are still present in Punjab, Pakistan. This may be due to a lower exposure rate to the mortality factor than in India, or may reflect a westward expansion of a hypothetical infectious agent or other cause, which has yet to lead to declines of the magnitude observed in India. Continued monitoring will be required to test the hypothesis that observed mortality rate will lead to a reduction in the breeding population in future seasons. The need to continue the diagnostic work already underway should be considered of utmost importance. Priority should be given to identifying the mortality factor and understanding the manner of its interaction with the vulture population, with the ultimate aim of reducing exposure or increasing resistance of the remaining wild birds, sufficient to allow the population to recover.

\section{Acknowledgements}

Funding for this project was received from the Gordon and Betty Moore Foundation, UN Foundation, The Walt Disney Company Foundation Conservation Awards, and the Zoological Society of San Diego. We would like to thank the following individuals and organizations for their partnership, help and cooperation: in Pakistan, the Ornithological Society of Pakistan (OSP), Brigadier Mukhtar Ahmed, Punjab Department of Wildlife and Parks, Lahore Zoo, National Council for the Conservation of Wildlife (NCCW), B.Z. Multan University, University of Agriculture at Faisalabad, Sind Wildlife Management Board, Zoological Survey Department Pakistan, WWF (Pakistan) and Pakistan Museum of Natural History; in Nepal, Bird Conservation Nepal (BCN), Himalayan Nature, Koshi Camp, and Department of National Parks and Wildlife Conservation (DNPWC). In the USA, The Zoological Society of San Diego, Washington State University and the Bodega Bay Institute. We also thank Asim for his invaluable assistance and Ramzan for his tireless and dedicated field efforts.

\section{References}

Ali, S. and Ripley, S. D. (1968) Handbook of the birds of India and Pakistan together with those of Nepal, Bhutan and Ceylon, I. Divers to hawks. Oxford: Oxford University Press.

Amadon, D. (1964) The evolution of low reproductive rates in birds. Evolution 18: 105110.

Benson, P. C. (2000) Causes of Cape Vulture Gyps coprotheres mortality at the Kransberg colony: a 17 year update. In R. D. Chancellor and B.-U. Meyburg, eds. Raptors at Risk. Proceedings of the $V$ World Conference on Birds of Prey and Owls. Midrand, Johannesburg, South Africa, 4-11 August 1998. 
Benson, P. C., Tarboton, W. R., Allan, D. G. and Dobbs, J. C. (1990) The breeding status of the Cape Vulture in the Transvaal during 1980-1985 Ostrich 61: 134-142.

BirdLife International (2001) Threatened birds of Asia: the Birdlife International Red Data Book. Cambridge, U.K.: BirdLife International.

Bowman, T. D, Schempf, P. F. and Bernatowicz, J. A. (1995) Bald Eagle survival and population dynamics in Alaska after the Exxon Valdez oil spill. J. Wildl. Manag. 59: 317324.

Cunningham, A., Prakash, V., Ghalsasi, G. R. and Pain, D. (2001) Investigating the cause of catastrophic declines in Asian Griffon Vultures, Gyps indicus and G. bengalensis. In T. Katzner and J. Parry-Jones, eds. Reports from the workshop on Indian Gyps Vultures.

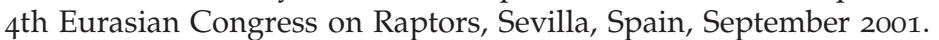

Houston, D. C. (1974) Mortality of the Cape Vulture. Ostrich 45: 57-62.

Houston, D. C. (1976) Breeding of the White-backed and Rüppell's Griffon Vultures, Gyps africanus and G. rueppellii. Ibis 118: 14-39.

Lumeij, J. T. (1994) Nephrology. Pp. 538-555 in B. W. Ritchie, G. J. Harrison L. R. and Harrison, eds. Avian medicine: principles and application. Lake Worth: Wingers Publishing. Mayfield, H. F. (1975) Suggestions for calculating nest success. Wilson Bull. 87: 456-466.

Mundy, P., Butchart, D., Ledger, J. A. and Piper, S. E. (1992) The vultures of Africa. South Africa: Acorn Books.

Newton, I. (1979) Population ecology of raptors. Berkhamsted, U.K.: Poyser.

Oaks, J. L., Rideout, B. A., Gilbert, M., Watson, R. T., Virani, M. Z. and Khan, A. A. (2001) Summary of diagnostic investigation into vulture mortality: Punjab Province, Pakistan, 2000-2001. In T. Katzner and J. Parry-Jones, eds. Reports from the workshop on Indian Gyps Vultures. 4th Eurasian Congress on Raptors, Sevilla, Spain, September 2001.

Pain, D. J. (2001) Conservation of critically endangered Gyps vultures in India. In L. Bennun and M. Virani, eds. Responding to the Asian vulture crisis: planning for vulture monitoring and conservation in Kenya. Proceedings and recommendations of a seminar and workshop held at the National Museums of Kenya, May 2001. NMK Ornithology Research report 41, June 2001.

Piper, S. E., Mundy, P. J. and Ledger, J. A. (1981) Estimates of survival in the Cape Vulture Gyps corprotheres. J. of Anim. Ecol. 50: 815-825.

Postupalsky S. (1974) Raptor reproductive success: some problems with methods, criteria, and terminology. Pp. 21-31 in F. N. Hamerstrom, Jr., B. E. Harrell and R. R. Olendorff, eds, Management of raptors, Proceedings of the conference on raptor conservation techniques, Fort Collins, CO: 22-24 March, 1973 (part 4). Raptor Research report 2.

Prakash, V. (1999) Status of vultures in Keoladeo National Park, Bharatpur, Rajasthan with special reference to population crash in Gyps species. J. Bombay Nat. Hist. Soc. 96: 365-378.

Prakash, V. and Rahmani, A. R. (1999) Notes about the decline of Indian vultures with particular reference to Keoladeo National Park. Vulture News 41: 6-13.

Prakash, V. (2001) Status and distribution of vultures in India with special reference to the population crash in Gyps species of vultures. In T. Katzner and J. Parry-Jones, eds. Reports from the workshop on Indian Gyps vultures. 4th Eurasian Congress on Raptors, Sevilla, Spain, September 2000.

Roberts, T. J. (1991) The birds of Pakistan, 1. Non-passeriformes. Oxford: Oxford University Press.

Robertson, A. S. (1984) Aspects of the population dynamics of Cape Vultures in the Cape Province. Ostrich 55: 196-206.

Robertson, A. S. (1985) Observations on the post-fledging dependence period of Cape vultures. Ostrich 56: 58-66.

Sharma, I., K. (1970) Breeding of Indian White-backed Vulture at Jodhpur. Ostrich 41: 205207. 
Wallace, M. P., Parker, P. G. and Temple, S. A (1980) An evaluation of patagial markers for cathartid vultures. J. Field Orni. 51: 309-428.

Watson, R. T. (1990) Population dynamics of the Bateleur in the Kruger National Park. Ostrich 61: 5-12.

Wynne-Edwards, V. C. (1955) Low reproductive rates in birds, especially sea-birds. Pp. 540-547 in Acta XI. International Ornithological Congress, 1954.

MARTIN GILBERT, MUNIR Z. VIRANI and RICHARD T. WATSON,

The Peregrine Fund, 5668 West Flying Hawk Lane, Boise, Idaho, 83709, USA.

E-mail: mart_gilbert@yahoo.com

J. LINDSAY OAKS

Department of Veterinary Microbiology and Pathology, Washington State University, Pullman, Washington 99164-7040 USA.

PATRICK C. BENSON

School of Animal, Plant and Environmental Sciences, University of the Witwatersrand, Private Bag 3, P.O. WITS, 2050, Johannesburg, Republic of South Africa.

ALEEM A. KHAN, SHAKEEL AHMED, JAMSHED CHAUDHRY, MUHAMMAD ARSHAD, SHAHID MAHMOOD and QASWAR ALI SHAH

Ornithological Society of Pakistan, 109/D P.O Box 73, Dera Ghazi Khan, Pakistan.

Received 15 January 2002; revision accepted 5 July 2002 